\title{
El archivo como experiencia estética: aproximaciones a un montaje digital
}

Laura Álvarez*

Si hay una preocupación y un sufrimiento en torno al archivo es porque sabemos que todo puede ser destruido sin resto. No solamente sin huella de lo que ha sido, sino sin memoria de la huella, sin el nombre de la huella.

Y eso es a la vez la amenaza del archivo y la posibilidad del archivo.

El archivo debe estar afuera, expuesto afuera.

Jacques Derrida

¿Qué es un libro en sí mismo? Un libro es un objeto físico en un mundo de objetos físicos. Es un conjunto de símbolos muertos.

Y entonces llega el lector adecuado, y las palabras... surgen a la vida, y asistimos a una resurrección del mundo.

Jorge Luis Borges

\section{Introducción}

El archivo personal no cuenta historias sino que son las narraciones secundarias las que le dan alguna coherencia significativa a sus elementos discontinuos. ${ }^{1}$ Partimos de una escisión entre el documento y la historia de ese documento. Ernst Wolfgang considera al archivo como un esqueleto de discurso-relato en el que se manifiestan espacios intermedios, agujeros y silencios. ${ }^{2}$ Es desde allí, que nos interesa mantener una mirada de carácter estético sobre el archivo convertido en un objeto susceptible de ser intervenido con un montaje, al estilo de los escritos de Walter Benjamín. ${ }^{3}$

\section{UBA-UNTREF}

1 El presente trabajo corresponde a los avances de la investigación sobre el Fondo Alberto Collazo dirigido por la Dra. Ma. Cristina Rossi en el Instituto de Investigaciones en Arte y Cultura "Norberto Griffa", UNTREF (Universidad Nacional de Tres de Febrero) y se inscribe en las indagaciones que estoy realizando para desarrollar mi proyecto de Tesis de la Maestría de Curaduría en Artes Visuales.

2 Ernst Wolfgang, "El archivo como metáfora. Del espacio de archivo al tiempo de archivo", en Nimio, n 5, Facultad de Bellas Artes, Universidad Nacional de La Plata, 2018 [2004]. Disponible en http://papelcosido.fba. unlp.edu.ar/nimio.

3 "De ese modo, la estrategia del montaje pretende deponer cualquier sistema de significación simbólica, en pos de una nueva ordenación en donde el sentido que se instituye surge del contraste iluminador de los elementos". Nicolás López, "El principio de montaje en Walter Benjamin", en Revista Lindes: Estudios Sociales del Arte y la Cultura, $n^{\circ}$ 6, Buenos Aires, 2013, p. 6.
Como unidad discursiva, esta operación realizada desde la mirada de un curador como arconte de ese archivo, ${ }^{4}$ recompone un sentido nuevo a partir de imágenes y fragmentos dispersos que no permitirá acceder a la totalidad de la historia en cuestión, sino a una infinita aproximación al acontecimiento, una respuesta productiva e interpretativa al sinsentido aparente de multiplicidad. ${ }^{5}$

Ante la creciente tendencia a la digitalización de los fondos, en el presente trabajo intentaremos plantear un abordaje que priorice la recepción de diversos públicos interesados en el acceso a los archivos personales (historiadores, investigadores, críticos, instituciones, y público en general). Desde esta perspectiva, la propuesta consiste en focalizar la descripción, consulta y presentación de los contenidos desde una pieza discursiva curada, en un formato de presentación de montaje digital indicial y no-narrativo. Trataremos de analizar la viabilidad de este recurso como una herramienta de comprensión para el lector de ese acervo y

$4 \quad$ Arcontes son los cuidadores del archivo, quienes lo interpretan; se trata de una dimensión política, una intención que está ejercida como capacidad de interpretación. Jacques Derrida, Mal de archivo: una impresión freudiana, Madrid, Trotta, 1997.

5 Didi Huberman diría "...aquello candente de la historia que no necesita del absoluto". Georges Didi Huberman, "El archivo arde (Das Archiv brennt)", en Georges Didi-Huberman y Knut Ebeling (eds.), Das Archiv brennt, Berlin, Kadmos, 2012 [2007]. Traducción de Juan Ennis. Recuperado de http://filologiaunlp.wordpress.com/bibliografia/ (Febrero 2019). 
su operación de lectura alternativa y transversal de los datos indicios, documentos, audios, videos, catálogos y las diversas piezas en la multiplicidad de formatos que hoy se presentan como materiales en los archivos personales.

La noción discursiva de tipo materialista (dado que involucra elementos singulares más allá del conjunto de textos) atravesará todo el recorrido de este análisis. Se propone considerar a los signos o relaciones que surgen "entre" los documentos de un archivo, para hacer surgir así una legibilidad de cómo funcionó la ley o el discurso que los ordenó y, de esta forma, poder mostrarlo para un lector o receptor, más allá de sus contenidos específicos. Es desde allí que se propone una mirada de carácter estético $y$, al mismo tiempo, creativa sobre el objeto: como un signo que puede ser relevante para construir un nuevo relato, disociando textos unidos y articulando elementos, aparentemente, heterogéneos, de una forma lúdica y dinámica.

\section{Hoy, el primer contacto es digital}

Los museos e instituciones del campo artístico se están adaptando a los públicos de la era digital y sus nuevas formas de consumo cultural. Las expectativas en términos de experiencias por parte de estas generaciones son altas, sean en forma presencial o virtual. La posibilidad de conocer las colecciones a partir del acceso digital, deposita en dicho canal un importante grado interés en términos de facilidad para el acceso a la información.

"Los bienes de información requieren acceso, no posesión". ${ }^{6}$ La tecnología digital ha transformado la forma en que las personas aprehendemos, ya que el acceso a la información ha dejado de ser restringido. Este hecho ha permitido a los museos, instituciones y archivos, crecer exponencialmente en audiencias, las cuales pueden localizarse en los cinco continentes y también demandar experiencias interactivas a la altura de otros servicios digitales que emplean cotidianamente. El objetivo para diseñar y pensar en estos consumos culturales digitales es ayudarles a diseñar su visita y crearles expectativas de lo que van a ver, antes de que ingresen a una búsqueda exhaustiva, mucho más si esa búsqueda está relacionada con el campo del arte.

La tecnología digital y, específicamente, la web, debe contribuir a hacer llegar al arte (y todo lo que le rodea: publicaciones, documentos de archivo, investigación, etc.) a todos los públicos posibles; sea atendiendo a distintos grados de discapacidad, co-

6 De N. K. Hayles, "Codificando el significante: Repensando los proceso de significación en los medios digitales", en Conferencia en la Universidad de Humboldt. Berlín, Alemania. 2001. Citado por Ernst Wolfgang "El archivo como metáfora. Del espacio de archivo al tiempo de archivo en Nimio $n^{\circ}$ 5, Facultad de Bellas Artes, Universidad Nacional de La Plata, 2018, [2004] http://papelcosido.fba.unlp.edu.ar/nimio. nocimiento o desde cualquier plataforma para la mayor cantidad de niveles de entendimiento posible.

Hoy, la experiencia del arte involucra hasta aplicaciones de realidad aumentada y virtual. En los consumidores online, el catálogo digital reviste un aporte de valor sobre la propia visita física. La idea es relacionar obras, artistas, objetos, a través de formas de acceso más exploratorias que, a su vez, están encarnando nuevos relatos. Los archivos del arte y sus múltiples formatos y documentos no deberían quedarse a un lado en esta tendencia.

\section{La nueva dimensión de memoria cultural-tecnológica: el desafío de los distintos formatos de archivos en la era digital}

La memoria clásica de archivo nunca ha sido interactiva, sin embargo, Ernst Wolfgang define cómo los documentos en el espacio en red se vuelven temporalmente accesibles para la retroalimentación del usuario. El orden espacial y tradicional de archivo que todavía continúa en lugares físicos, ahora, está acompañado de una práctica dinámica de mapeo de datos, de operaciones, de procesos temporales y activos que diferencian a los archivos tradicionales de los electrónicos. El espacio se temporaliza, el paradigma de archivo es reemplazado por la transferencia de información permanente con memoria de reciclaje. De esta forma se deshace la supremacía tradicional de las letras en los archivos en papel; en cambio, entran a considerarse nuevos soportes en sonido e imágenes. La búsqueda en estos nuevos soportes, antes un tanto aleatoria, ahora se vuelve calculable y los distintos objetos pueden ser sometidos a algoritmos de reconocimiento de patrones más gobernados tecnológicamente: las melodías pueden recuperarse mediante melodías similares, las imágenes por imágenes, etc.. Desde el planteo de este autor, a partir de ahora, se generan perspectivas ópticas inesperadas a partir de un archivo audiovisual que, por primera vez, puede organizarse no solamente de acuerdo con los metadatos sino según sus propios lenguajes o formatos -memoria visual en su propio medio-. Este aspecto es mencionado en el presente trabajo para considerar los posibles beneficios de contar con un montaje discursivo que direccione la búsqueda, contemplando variables destacadas de algunos formatos para archivos personales específicos, de acuerdo a la trayectoria del artista/académico o al personaje de la cultura, según se trate.

\section{El problema de la escucha o recepción de la complejidad}

Desde la mirada que Jacques Derrida le brinda a su análisis fundacional del concepto de archivo, iniciamos el recorrido a partir 
de la etimología de la palabra para encontrar algunas respuestas que estamos buscando. Arkhé adopta un doble principio: es origen, fundamento, lo esencial de algo y, por otro lado, es mandato, es ley. Es un depósito en un lugar de autoridad. El principio de consignación, también es importante, consignatio, es decir: de qué manera se reúnen esos signos o el sello de signatura que le atribuye lógica a un conjunto de documentos. Los arcontes o los cuidadores del archivo, son quienes lo interpretan; ésta es una dimensión política, una intención que está ejercida como capacidad de interpretación. ${ }^{7}$ Para que este nivel de lectura sea interpretado obliga a disponer de herramientas que habiliten una intervención facilitadora para su comprensión.

El abordaje de la complejidad que un archivo personal digital plantea al usuario invita a citar las palabras de Ana María Guasch. La pregunta que surge en este primer nivel de análisis es ¿qué es lo más importante para el coleccionista-autor cuando arma su acervo?, ¿recuperar el pasado o preservarlo para el futuro? $y$, desde ese punto, nuestra primera reflexión: es allí en donde aparece la escucha a partir del presente y la necesidad de darle legibilidad para su entendimiento. ${ }^{8}$ El mayor desafío que nos planteamos en este trabajo es el de pensar los contenidos desde la apertura para mostrarlos.

Partimos de la discusión epistemológica que surge de la inestabilidad propia del archivo. Es desde esa inestabilidad que se sugiere una apertura para presentarlo; así, desde la actualidad, y a partir de un acontecimiento performático (el montaje) se dará cita a un nuevo status del objeto: su por-venir.

Contemplando la totalidad de piezas de un archivo desde una doble perspectiva (la global y la particular), consideramos importante poner en foco la parte del todo. En palabras de Marisol Salanova Burguera, "Toda parte del archivo es un elemento de la realidad por su aparición en un tiempo histórico dado pero es sobre esta aparición sobre la que hay que trabajar, pues a partir de ella se puede descifrar su sentido". ${ }^{9}$

En la digitalización de archivos personales, se visibilizan nuevas condiciones acerca de la recepción del objeto y, al mismo tiempo, desde una arqueología de los medios, en lugar de una memoria narrativa, se delinea una cultura digital que trabaja con una me-

7 Jacques Derrida, Mal de archivo. Una impresión freudiana, op. cit..

8 A partir de aquí nos referiremos a la figura coleccionista-autor desde la noción de Ana María Guasch. El "coleccionista" de un acervo, como una especie de autor con escritura propia, definida por su mismo acto de guardar. La intención que le imprime a dicho acto, su vocación, por qué lo realiza, todo "habla". En los archivos personales, esta intención discursiva aparece en el ordenamiento por parte del coleccionista y de sus propios papeles. Ana María Guasch, "El giro de la memoria y el giro del archivo en las prácticas artísticas contemporáneas", en Revista 180, Santiago de Chile, Universidad Diego Portales, 2012, p. 4.

9 Marisol Salanova Burguera, "Deus ex machina. Art, Emotion and Value", en 5 th Mediterranean Congress of Aesthetics, Valencia, Universidad de Valencia, 2011, p. 3. moria que calcula. Desde esta concepción se redefine y se pasa de un espacio de archivo a un tiempo de archivo, con dinámica de transmisión permanente de datos. ${ }^{10}$

En términos de tiempo, el archivo representa el "ayer" de cualquier tipo de poder ejercido en una época. Desde una perspectiva foucaultiana, estaríamos trabajando con una historia, contada desde otro tiempo, por un otro, que vivió en un contexto determinado y que pone de manifiesto una lógica que hay que recuperar desde el presente."

Ese "ahora", se lleva a cabo desde una intervención en formato de recepción, a través de una lectura de la lógica que reunió a esos documentos. Nos referimos al "entre", una superficie discursiva de sentido que deberíamos intentar descifrar. Parte del proyecto es determinar cómo funcionó esa ley para poder ofrecer esos "destellos" a los receptores. ${ }^{12}$ Podríamos afirmar que estalla el archivo como unidad y sale a buscar sus datos relevantes de cara a una pieza indicial que reorganice la mirada sobre algunos de sus elementos.

Aquí es donde sugerimos, desde esta dimensión política, la posibilidad de recomponer una mirada del archivo como objeto de estética, un impulso ejercido como voluntad; parafraseando a Hal Foster diríamos que el propósito de cualquier "arqueología" es determinar lo que uno puede desde la diferencia del presente y el potencial del pasado. ${ }^{13}$ Encarnar la voluntad de relacionar: de explorar un pasado perdido, de recopilar sus diferentes signos (a veces de forma pragmática, a veces en forma de parodias), de determinar lo que podría quedar para el hoy.

Entonces, en el contexto de esta reflexión diríamos que el "problema de la escucha o recepción" del archivo y su inherente complejidad de lectura — debido a que está abierto a una comunidad diversa, que no siempre tiene el mismo conocimiento para su comprensión-, requiere de un determinado tipo de intervención, que este trabajo propone abordar desde una herramienta de montaje discursivo inicial.

10 Ernst Wolfgang, "El archivo como metáfora. Del espacio de archivo al tiempo de archivo", en Nimio, n 5, Facultad de Bellas Artes, Universidad Nacional de La Plata, 2018. [2004], Disponible en: http://papelcosido. fba.unlp.edu.ar/nimio

11 Michel Foucault, La arqueología del saber, México, Siglo XXI, 1977.

12 Estos "destellos" se comprenden a partir de la siguiente consideración: "...articular históricamente el pasado no significa conocerlo como verdaderamente ha sido. Significa adueñarse de un recuerdo tal y como éste relampaguea en un instante de peligro". Walter Benjamin, Conceptos de filosofía de la historia, La Plata, Terramar, 2007, p. 67. Traducción de H. A. Murena y D. J. Vogelmann.

13 Hal Foster, "El impulso de archivo", en Revista Nimio, La Plata, Facultad de Bellas Artes, Universidad Nacional de La Plata, 2016. 


\section{Repensar al Guernica: una presentación interactiva para conocer la obra más emblemática del siglo $\mathbf{X X}$, como ejemplo exitoso de montaje digital}

Para iniciar el ejercicio metodológico de un montaje de este tipo, haremos foco en el caso de una página web del Museo Reina Sofía en España con la pinacoteca "Repensar Guernica. Historia y conflicto del siglo XX". Con 80 años de historia, el fondo concentra el estudio del cuadro de Picasso a través de 1.939 documentos catalogados (más de 6.000 piezas relacionadas). Cuenta con 60 tipos/formatos de materiales entre fotografías, vídeos, noticiarios, periódicos, revistas, correspondencia institucional y personal, catálogos de exposiciones, carteles o folletos.

El proceso implicó el diseño de la visualización de un archivo que cuenta con la recopilación exhaustiva de todos los documentos relacionados con el cuadro y la cronología de la obra de arte española más emblemática del siglo XX. Se encaró un proyecto a través del asesoramiento de un desarrollador tecnológico y fue, hasta la fecha, el mayor estudio de imágenes de alta resolución que se ha realizado sobre una pintura. ${ }^{14}$

Como parte de ese proyecto, la portada se encarnó como un reto en el arte de contar con pocas palabras una gran historia, el llamado storytelling en la jerga corporativa. Según lo describen sus desarrolladores, el proceso comenzó preguntándose ¿cómo generar interés sobre esta base documental inédita a personas que apenas conocían el Guernica de Picasso? Había múltiples dimensiones de la información, y una sola oportunidad para atrapar al usuario. Susana Heredia, la experta en artes de la empresa de tecnología contaba:

Esta pieza fue una a las cuales dimos más vueltas... optamos por trabajar el storytelling con una navegación guiada en la que cuidamos cada detalle, cada frase, cada imagen. El lugar de contar esta historia era la propia portada de la web. La solución radica en ir presentando en la home, de forma interactiva y muy guiada, una serie de textos acompañados con imágenes que aparecen a medida que el usuario va haciendo scroll..$^{15}$

En términos generales, técnicamente, la programación del gestor de contenidos del sitio facilita la búsqueda entre los 2000 documentos relacionados entre sí.

La "cronología", una pieza interactiva inicial, es una herramienta de exploración del archivo documental del Guernica con un enfoque diferente al del buscador y en un rico formato de visuali- zación de datos. Concebida bajo el concepto de herramienta de conocimiento abierta, permite conectar a partir de un eje temporal, desde el nivel inicial del acceso al archivo general, todos los documentos del acervo, independientemente de su naturaleza. Además, como parte de una misma dinámica ese eje está acompañado de una línea superior que marca hitos históricos a nivel mundial que influenciaron en la historia y viajes del cuadro. Está diseñada para el descubrimiento y la inmersión. Tal como lo explican sus desarrolladores, de uso intuitivo y de una manera sencilla y visualmente muy atractiva y dinámica, es posible enlazar visualmente acontecimientos, quizás, inconexos en el tiempo pero significativos en el recorrido del relato de la obra.

Esta sección se diseñó a partir de una aplicación basada en javascript con animaciones de responsabilidad diferente: transacciones entre distintos slides (Fullpage.js) y escenas y animaciones encadenadas (GreenSock). Con estas funcionalidades el usuario podía obtener de su experiencia algo esencial: conseguir una narrativa fluida, que diera el tiempo justo para leer y sentirse dentro de la historia que querían contarle y adquirir un ritmo de lectura secuenciado y enlazado al modo de un relato.

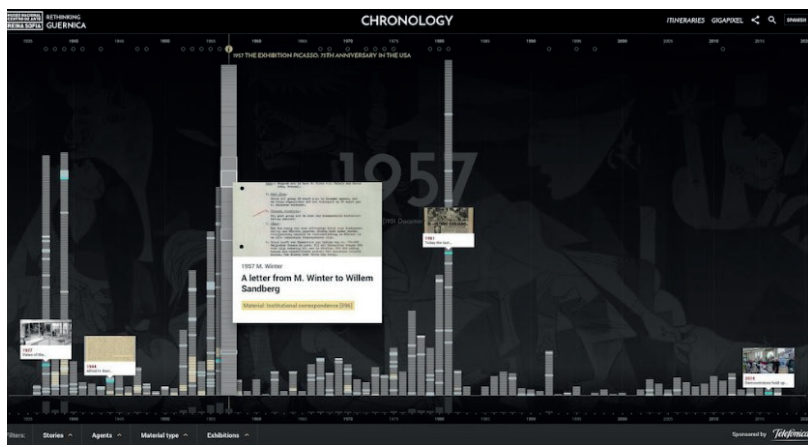

Figura 1: Captura de pantalla de la sección "Cronologia" (sitio Repensar el Guernica, Museo Reina Sofía)

La flexibilidad, innovación y las posibilidades de interacción que se concretaron a partir de este desarrollo para una web institucional fueron reconocidas por la comunidad de expertos al punto que el sitio recibió dos de los premios más importantes en comunicación online para audiencias: entre ellos el premio a la mejor web de una institución cultural, 2018 (premio Webby) y el GLA$\mathrm{Mi}$ (anteriormente conocidos como Best of the Web Awards). Los GLAMi son concedidos por Museums and the Web, una institución que pretende dar visibilidad a proyectos innovadores en el ámbito de la cultura y que ayuden a acercar este sector al público general.

14 Biko2, empresa desarrolladora del sitio Repensar el Guernica.

15 David Gil y Susana Heredia, "Qué hay detrás de Repensar el Guernica", Biko2, 2017. Disponible en: https://www.biko2.com/drupal/que-hay-detras-de-repensar-guernica/. 
El dispositivo: un montaje digital desde "el arte de contar un relato" para hacer surgir al acontecimiento

En esta instancia intentaremos abordar la validación de un enfoque/dispositivo, desde la mirada curatorial del campo del arte, conveniente para el objeto desde cinco aspectos importantes:

a. Desde la noción de archivo concebido no como origen sino como objeto de abordaje arqueológico, digital y común:16

b. para la presentación de la diversidad de formatos presentes en los archivos personales;

c. para soportar la tendencia del viraje hacia lo audiovisual en el campo de la archivística en el arte;

d. La posibilidad de interconectar archivos y acervos existentes en distintos espacios físicos o institucionales, como en el caso del fondo de Alberto Collazo que se encuentra compartido con la Fundación Espigas, o el archivo de Rubén Darío, ordenado y centralizado (AR.DOC) que está distribuido en diversas partes del mundo, digitalizado;" ${ }^{7}$

e. La idea de concebir un dispositivo discursivo digital, que esté presente al momento de ingresar al sitio del fondo, como una subpágina, que acerque y piense los papeles, las fotografías, grabaciones, catálogos, videos, afiches, manifiestos como acontecimientos; es una forma de poner en acción a los materiales, desplegando sus posibilidades, las mismas que los especialistas e investigadores acostumbran a interrogar para escribir sus propios relatos.

De esta forma, la tarea en el diseño de esta pieza redundaría en explorar el archivo como "esqueleto" de un discurso de un otro, con múltiples dimensiones, activando una escucha para captar los intersticios en los que, desde el hoy, se puedan recuperar hallazgos en dicha lectura.

\section{Potencialidades estéticas del archivo, pensar el archivo como imagen}

En este sentido, nos enfocaremos brevemente en los signos que permiten pensar en el objeto archivo como susceptible de ser intervenido como imagen. María Eugenia Rasic se dedica a las zonas de presencias y ausencias del archivo como materiales para producir imágenes. ${ }^{18}$ Así, los modos de los procesos de escritura

16 Daniel Link y Rodrigo Caresani, "Saberes del archivo en la era de la reproductibilidad digital: un prototipo para Rubén Darío", en Virtualis, vol. 9, $n^{\circ} 17$, México, Dirección de Investigación de la Escuela de Humanidades y Educación, 2018 http://www.revistavirtualis.mx/index.php/virtualis/ article/view/273/264

17 De acuerdo al autor, esta experiencia, puntualmente es extitucional, mundana, provisional y, por eso mismo, profundamente política. Daniel Link y R. J. Caresani, Ibíd.

18 En el artículo se profundiza acerca de la dimensión estética a partir de de cada coleccionista-autor se manifestarán como espacio para la experiencia estética, como imagen suspendida en un tiempo y un espacio otro, como imagen pintada y con cadencia: como experiencia estética ante todo. La posibilidad que habilita esta forma de intervenir en el archivo, según esta autora, es navegar su espacio explorando mecanismos de escritura que desvíen los sentidos de lectura teleológica (con análisis más esenciales acerca de la finalidad u objetivos de esos documentos) invitando a sus contenidos a espaciarse y convertirse en "destellos" de una imagen para ser percibida. ${ }^{19}$

Es, justamente, desde esa imagen sobre la que proponemos producir un discurso y para ello, precisamente, traer la concepción del montaje que produce Walter Benjamin. Nicolás López analizó en profundidad el método de montaje literario de W. Benjamin y para nuestra reflexión consideramos que resulta apropiado a los efectos de la aplicación de esos mismos criterios para la operación de montaje a realizar en el archivo. ${ }^{20}$ Para Benjamin, el montaje surgió ante la experiencia de la disolución y, sobre todo, de la dispersión de las cosas mismas en el caos de la gran ciudad -lo que supone un trabajo positivo sobre las ruinas y desperdicios de la historia. Desde esta mirada, se ensaya una idea de componer los materiales de una manera en que no se supediten a una lógica de ordenación jerárquica o relato lineal sino al impulso de representar situaciones, conexiones aleatorias de ese relato en acción. Se trata de un modo de reflejar dichas situaciones que surge como un "descubrimiento", una suspensión en la que cada situación adquiere una relativa independencia autónoma.

Uno de los puntos más destacados de este enfoque es el que menciona lo que ésta operación produce en el espectador. El modo de presentación de esta producción busca generar un "extrañamiento" (con efecto de distanciamiento) en el público que lo recibe, que de alguna manera interrumpe el continuum de la "escucha" para dejar caer la ilusión de un mundo relatado - que en el caso del archivo sería encarnado por el catálogo a partir de la enumeración de los documentos presentes- y abrir el espacio para la reflexión crítica, desde una dimensión didáctica, que obliga al espectador a adoptar una postura ante la situación. Según conceptos del propio Benjamin, el efecto de ese impacto de distanciamiento se acerca a un "momento pos-aurático de re-

la forma de escritura de un archivo por su autor: "...Entramos y salimos de las hojas para explorar ese espaciamiento, y vamos armando de este modo nuestras propias rutas de acceso al archivo. Vamos detectando en el recorrido zonas: zonas de profundidad, zonas de desborde, zonas de repitencia...operar con manuscritos de autor es trabajar con la imagen: imagen de lo escrito, de lo acromatizable, de lo dicho, del silencio, de lo imaginable y lo que está por venir", María Eugenia Rasic, "El contacto con manuscritos de autor: una experiencia estética posible", ponencia presentada en las VI Jornadas Internacionales de Filología y Lingüística y Primeras de Crítica Genética: "Las lenguas del archivo", La Plata, 2013. Disponible en: http://jornadasfilologiaylinguistica.fahce.unlp.edu.ar.

19 María Eugenia Rasic, "El contacto con manuscritos de autor: una experiencia estética posible", op. cit..

20 Nicolás López. "El principio de montaje en Walter Benjamin", op. cit.. 
cepción que sustituye a la contemplación como ritmo". Nosotros diríamos que esta operación instituye un cambio de posición más activa para el que consulta el archivo.

Cómo técnica o método para acceder al archivo, podremos dar cita a la capacidad de alterar la percepción humana mediante la exposición a relaciones nuevas y, también, como respuesta productiva al sinsentido aparente de la multiplicidad de documentos de cada acervo. No estaríamos descubriendo los documentos tal cual fueron (propios de un pasado neutro y clausurado) sino que se mostrarían bajo un nuevo ordenamiento. Se llevarían a esta renovada perspectiva los aspectos más actuales del pasado que se compondrían desde un nuevo sentido para abordarlos. El contenido, de esta forma, redundará en dar a conocer, mostrar o hacer surgir una legibilidad alternativa de cómo funcionó la ley o el discurso que los ordenó, más allá de sus documentos.

\section{El fondo Alberto Collazo, el caso local para ensayar un relato de apertura a través de una pieza de montaje}

A partir de la ponencia realizada por Olga Zurita en las jornadas anteriores de este mismo congreso en 2017, se mencionaba las características generales del archivo de Alberto Collazo a saber: documentos manuscritos y editados que se reunieron de forma temática, en relación a su especificidad y con la finalidad de informar y no la de servir como prueba o testimonio de algo (no teleológico). ${ }^{21} \mathrm{El}$ acervo contiene agrupaciones o series documentales y documentos sueltos. Las primeras llegaron organizadas por áreas, con el criterio de agrupación utilizada por el coleccionista, y fueron agrupadas por artistas, —correspondencia, folletos, catálogos, fotos de obra, diapositivas, publicaciones no periódicas, notas manuscritos, entre otros-. Con los documentos sueltos, en cambio, se evaluó la información contenida y se los agrupó en cada una de las categorías creadas por el coleccionista-autor en forma cronológica.

En términos de comenzar metodológicamente a definir un criterio para una curaduría de contenidos a "mostrar", la noción tiempo y contextualización de hitos en el campo del arte puede ser un muy buen camino, dado que es lo que todo lo une. En un archivo personal como en el del Fondo Collazo, permitiría unir las decisiones y acciones protagonizadas por este crítico de arte y así convertirse en un posible recorrido para su presentación, al igual que en el caso del Guernica.

21 Olga Zurita, "Trabajo interdisciplinario en la puesta en valor de las colecciones documentales vinculado al arte y la cultura. El Archivo Dr. Norberto Griffa del IIAC", en María Virginia Castro y María Eugenia Sik, (comps.), Actas de las II Jornadas de Discusión / I Congreso Internacional: Los archivos personales: prácticas archivísticas, problemas metodológicos y usos historiográficos, Buenos Aires, CeDInCl, 2017 pp. 177-187. Disponible en: http://cedinci.unsam.edu.ar/pdf/jornadas/Actas-Archivos-Personales.pdf
Otra dimensión que quizás se puede explorar para el diseño de un formato de visualización a partir de un montaje, en el caso puntual de Alberto Collazo, serían los signos o aspectos que quedan "afuera" del análisis desde el catálogo, como los roles que el coleccionista-autor encarnó a lo largo de su trayectoria. Esta agrupación podría considerar una mirada transversal y más comprehensiva dentro del recorrido y visualización de hitos documentales.

Algunos interrogantes que podrían surgir para el desarrollo de esta pieza: ¿cómo se distribuyen los documentos durante la vida del coleccionista-autor? ¿Qué tal si ponemos en contexto temporal los hechos históricos e hitos de su participación en Bienales-congresos? ¿Las cartas y presentaciones de artistas podrían habilitar un rol de productor influyente dentro del arte latinoamericano? ¿Y si se propone algún recurso o aplicación digital que genere descubrimiento y sorpresa?. Al igual que los desarrollos de nubes de palabras, se pueden generar zooms en años de gran concentración de documentos y así evidenciar zonas de interés por actividad de distinta índole. ${ }^{22}$ El camino es infinito.

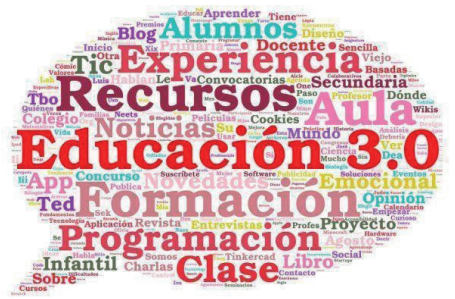

Figura 2: Referencia de la herramienta de "nube de palabras"

\section{Conclusión}

Retomando lo antedicho, nos interesa destacar que el archivo no es la base de la memoria histórica, sino su forma alternativa de conocimiento. La metáfora espacial del archivo se transforma en una dimensión temporal y en una oportunidad; la dinamización de los fondos en formato digital implica procedimientos basados en el tiempo y el montaje aparece como una posible forma para representarlo, dinámicamente.

Las posibilidades para el almacenamiento son innumerables y dejan a la legibilidad muy comprometida para el entendimiento del contenido global. El principio arcóntico que define J. Derrida y la intervención desde una noción arqueológica deberían estar como faro que guíen hacia la abarcabilidad.

22 Hace referencia a una herramienta de nube de etiquetas, es una de las formas más utilizadas por la mayoría de CMS (sistema de gestión de contenidos) que permiten crear páginas webs o blog, para resaltar las de una forma muy gráfica las palabras clave de un sitio web. 
Nuestra propuesta está sostenida desde la premisa que solo se puede localizar lo que se puede direccionar, procedimiento del que surgen las siguientes ventajas:

- $\quad$ nuevas formas de entender la relación entre pasado y presente

- $\quad$ innovadora actualización contemporánea de ese pasado a partir de sus huellas sobreviviendo en el presente

- recomposición de un sentido nuevo (de tipo digital que debe ser temporario y dinámico) a partir de fragmentos clave en cada archivo, dispersos, pero ávidos de ser capturados como señales para un recorrido transversal.

Este por-venir del archivo, entonces, interrumpe la relación con el registro de lo que es, teleológicamente hablando, para que surja como performativo. Lo pone en suspenso y lo prepara para esa apertura. Este suceso no es ni reflejo del documento ni tampoco su demostración o prueba. "El montaje es el que permite darle consistencia a los jirones de saber, montaje que no permitirá acceder a la totalidad de la historia en cuestión, sino una infinita aproximación al acontecimiento". ${ }^{23}$ De este modo, consideramos que es significativo para quien acceda a la lectura o escucha de un archivo hacer surgir lo candente de una historia, que no necesita del absoluto y que, al mismo tiempo, encarna la unidad mínima de discurso que servirá como frase para su relato desde el presente.

\section{Referencias bibliográficas}

Benjamin, Walter. Conceptos de filosofía de la historia, La Plata, Terramar. 2007.

Borges, Jorge Luis, Arte Poética. Seis conferencias, Buenos Aires, Editorial Austral, 2001

Derrida, Jacques, "Archivo y borrador", en: Goldchluk, G. y Pené, M. (comps.) Palabras de archivo, Santa Fe, Editorial UNL, 2013 [1995].

Derrida, Jacques, Mal de archivo. Una impresión freudiana, Madrid, Trotta, 1997.

Didi-Huberman, Georges y Ebeling, Knut (eds.), Das Archiv brennt, Berlin, Kadmos, 2012 [2007].

Foster, Hal, "El impulso de archivo", en Revista Nimio, La Plata, Facultad de Bellas Artes, Universidad Nacional de La Plata, 2016.

23 Natali Incaminato, "El archivo resiste", ponencia presentada en las VI Jornadas Internacionales de Filología y Lingüística y Primeras de Crítica Genética "Las lenguas del archivo", La Plata, 2013 (http://jornadasfilologiaylinguistica.fahce.unlp.edu.ar recuperado en febrero 2019).
Foucault, Michel, La arqueología del saber, México, Siglo XXI, 1977.

Goldchluk, Graciela, "Archivo y domicilio: el lugar del archivo", en VI Jornadas Internacionales de Filología y Lingüística y Primeras de Crítica Genética "Las lenguas del archivo", Buenos Aires, Argentina, Universidad de la Plata, 2013.

Guasch, Ana María, "El giro de la memoria y el giro del archivo en las prácticas artísticas contemporáneas", en Revista 180, Santiago de Chile, Universidad Diego Portales, 2012.

Incaminato, Natali, "El archivo resiste", ponencia en VI Jornadas Internacionales de Filología y Lingüística y Primeras de Crítica Genética "Las lenguas del archivo", La Plata, 2013 (http://jornadasfilologiaylinguistica.fahce.unlp.edu.ar recuperado en febrero 2019).

Link, Daniel y Caresani, Rodrigo J., "Saberes del archivo en la era de la reproductibilidad digital: un prototipo para Rubén Darío", en Virtualis, vol. 9, n 17, México, Dirección de Investigación de la Escuela de Humanidades y Educación, 2018 http://www.revistavirtualis.mx/index.php/virtualis/article/view/273/264.

López, Nicolás, "El principio de montaje en Walter Benjamin", en Revista Lindes. Estudios Sociales del Arte y la Cultura, $n^{\circ} 6$, Buenos Aires, 2013

Rasic, María Eugenia. "El contacto con manuscritos de autor: una experiencia estética posible" en VI Jornadas Internacionales de Filología y Lingüística y Primeras de Crítica Genética "Las lenguas del archivo" La Plata, 2013. Disponible en http://jornadasfilologiaylinguistica.fahce.unlp.edu.ar

Salanova Burguera, Marisol, "Deus ex machina. Art, Emotion and Value", en 5th Mediterranean Congress of Aesthetics, Valencia, Universidad de Valencia, 2011.

Tacetta, Natalia y Ulanovsky Lucía. "Archivos que arden", registros de audio del curso en Centro de Investigaciones Artísticas (CIA), Buenos Aires, Junio-agosto 2018.

"Repensar el Guernica" web (subsitio del Museo Reina Sofia, Madrid, España https://guernica.museoreinasofia.es/

Gil, David y Heredia, Susana, "Qué hay detrás de Repensar el Guernica", Biko2, 2017, disponible en https://www.biko2.com/ drupal/que-hay-detras-de-repensar-guernica/

WILA, "Museos y centros de arte en el S XXI. Claves de su transformación digital", Biko2, 2019. Disponible en https://www. biko2.com/actualidad-biko/museos-y-centros-de-arte-en-el-s-xxi- 
claves-de-su-transformacion-digital/

Zurita, Olga, "Trabajo interdisciplinario en la puesta en valor de las colecciones documentales vinculado al arte y la cultura. El Archivo Dr. Norberto Griffa del IIAC", en María Virginia Castro y María Eugenia Sik, (comps.), Actas de las II Jornadas de Discusión / I Congreso Internacional: Los archivos personales: prácticas archivísticas, problemas metodológicos y usos historiográficos, Buenos Aires, CeDInCl, 2017, pp. 177-187. Disponible en http://cedinci.unsam.edu.ar/pdf/jornadas/Actas-Archivos-Personales.pdf

Wolfgang, Ernst, "El archivo como metáfora. Del espacio de archivo al tiempo de archivo", en Nimio, n 5, Facultad de Bellas Artes. Universidad Nacional de La Plata. 2018 . [2004] http:// papelcosido.fba.unlp.edu.ar/nimio (recuperado en febrero 2019).

\section{Resumen}

Ante la creciente tendencia a la digitalización de los fondos, se plantea un abordaje que prioriza la recepción de diversos públicos interesados en el acceso a los archivos personales (historiadores, investigadores, críticos, instituciones, y público en general). Nuestro trabajo se ubica en la discusión epistemológica que surge de la inestabilidad propia del archivo $y$, a partir de ella, se sugiere una apertura para mostrarlo, desde el presente, proponiendo un acontecimiento performático (el montaje) que dará cita a un nuevo status del objeto: su por-venir. La propuesta consiste en focalizar la descripción, consulta y presentación de los contenidos de un acervo desde la curaduría y el montaje digital.

Palabras clave: Receptor - Montaje - Relato - Autor Indicios - Escucha - Imagen.

\section{Abstract:}

The archive as an aesthetic experience: approaches to a digital montage

Given the growing trend towards the digitalization of archives, an approach that prioritizes the reception of diverse audiences interested in access to personal archives (historians, researchers, critics, institutions, and the general public) is proposed. Our work is focused in the epistemological discussion that arises from the instability of the archive itself and, from it, an opening is suggested to show it, from the present, proposing a performative event (the digital mounting) that will give rise to a new status of the Object: their future. The proposal consists in focusing the description, consultation and presentation of the contents of a collection from the curatorship and digital mounting.

Key words: Receiver - Assembly - Story - Author Clues - Listen - Image.

Recibido el 20/06/2019 Aceptado el 13/09/2019 